\title{
FOR WORK / BEKISTING PADA BANGUNAN GEDUNG BERTINGKAT
}

\author{
Budhi Dharma \\ Program Studi Diploma III Teknik Sipil \\ Fakultas Teknik Universitas Diponegoro
}

\begin{abstract}
Budhi Dharma, in this paper explain that to get a good concrete structure form, need the existence of making of work form (bekisting) the goodness. In this case accuration, strength and also the supporter structure of having to enough of strength. To facilitate installation and also time efficiency in execution of unloading and installation need a correct and good construction.
\end{abstract}

Keywords:bekesting, structure strength

\section{PENDAHULUAN}

Pekerjaan konstruksi beton merupakan perpaduan/gabungan dari beton, besi tulangan, dimana dalam mewujudkan struktur beton tersebut memerlukan suatu cetakan .

Agar dapat membentuk suatu struktur yang sesuai dengan tampak Arsitektur, cetakan harus dibuat dengan tepat ukurannya. Bahkan yang biasa dipakai antara lain : papan bekisting, kayu lapis/multiplek, lembaran plat besi/baja, profil lembaran besi/baja ataupun alluminium.

Konstruksi penunjang dalam membentuk struktur, antara lain berupa : perancah / steiger dari bahan : bambu, dolken, balok kayu atau rangkaian pipa, scaffolding. Dll.

Kecepatan, kemudahan dalam memasang dan membongkar bekisting tersebut sangat menentukan hasil beton yang diperoleh. Untuk beton Expose, presisi pembuatan cetakan/bekisting sangat penting, kelurusan arah vertical dan horizontal harus teliti, sehingga hasil beton tidak perlu adanya perbaikan.

Pada pekerjaan beton yang banyak, direncanakan cetakan yang dapat dipakai berulang kali, sehingga cetakan harus kuat, mudah dibongkar dan dapat dipakai kembali.

Merencanakan suatu cetakan, selain ditentukan oleh bentuk (arsitektur), jenis beton , juga diperhitungkan terhadap beban yang akan dipikulnya.

Cetakan yang baik harus memenuhi persyaratan dan mudah untuk dibongkar, sehingga dapat menghemat waktu pelaksanaan , bahan dan tenaga.

Kekuatan penunjang/perancah sangat mempengaruhi hasil pengecoran beton, demikian pula tanah yang menyangga harus kuat.

Apabila tanah masih perlu adanya pemadatan/perbaikan tanah, serta ditambah dengan landasan yang memadai.

\section{SURVEY / MARKING}

Untuk mendapatkan hasil yang tepat dalam melaksanakan pekerjaan, maka suvey merupakan hal yang penting guna merintis jalan untuk memulai pekerjaan dalam proyek.

Mengingat pentingnya survey, maka harus selalu dipilirkan cara agar dapat memberikan pedoman ( as - as ), sehingga setiap pekerja dilapangan mudah membacanya. Untuk hal tersebut perlu adanya perencanaan yang matang.

Penempatan Bench Mark (BM) pada level $\pm 0.00 \mathrm{~m}$ harus bebas dari terganggunya BM tersebut, dan diletakkan diluar bangunan
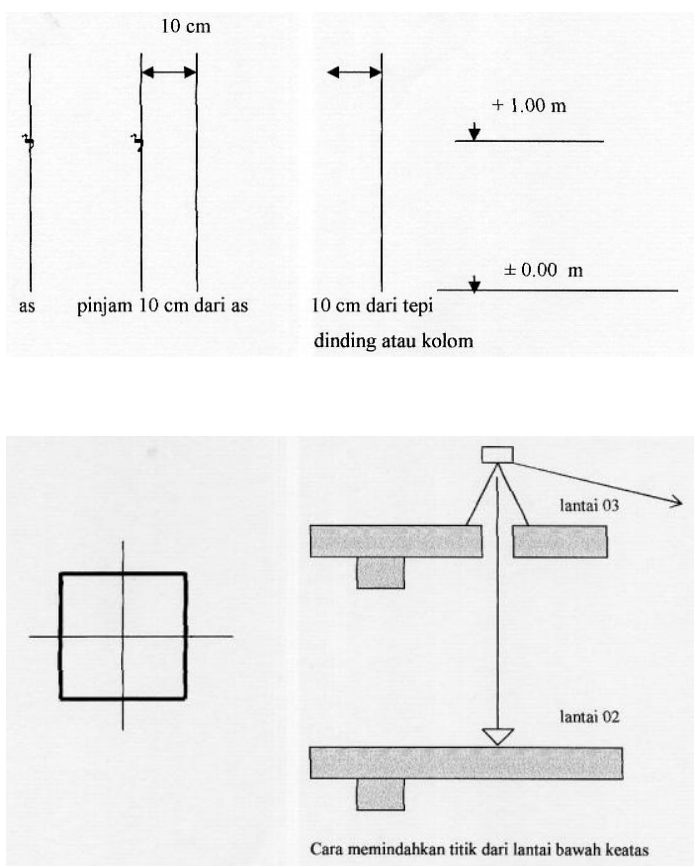

Gambar 1. Pemindahan titik ukur 


\section{PERHITUNGAN BEBAN UNTUK FORM WORK (CETAKAN)}

Slab / lantai

Yang perlu diperhitungkan adalah :

- berat sendiri beton

- kemungkinan tertumpukya beton pada suatu tempat

- beban hidup, peralatan, perlengkapan dll.

Tabel 1. Jenis pembebanan

\begin{tabular}{ll}
\hline \multicolumn{1}{c}{ JENIS BEBAN } & \multicolumn{2}{c}{ BERAT JENIS } \\
\hline a. Beton bertulang & $2.400 \mathrm{~kg} / \mathrm{m}^{3}$ \\
b. Beton ringan A & $2.000 \mathrm{~kg} / \mathrm{m}^{3}$ \\
c. Beton ringan B & $1.800 \mathrm{~kg} / \mathrm{m}^{3}$ \\
Kemungkinan & $1 / 2 \times$ pembebanan \\
pembebanan & akibat berat sendiri \\
setempat (akibat & beton $\left(\mathrm{kg} / \mathrm{m}^{2}\right)$ \\
bertumpuknya beton & \\
waktu pelaksanaan) & \\
Beban hidup & $150 \mathrm{~kg} / \mathrm{m}^{2}$ \\
\hline
\end{tabular}

Secara matematis pembebanan untuk cetakan lantai dapat dirumuskan :

$$
\begin{array}{ll}
\mathrm{W} & =\gamma \times 1,5 \mathrm{~d}+150 \\
\mathrm{~W} & =\text { beban } \\
\gamma & =\text { berat jenis beton }\left(\mathrm{kg} / \mathrm{m}^{3}\right) \\
\mathrm{d} & =\text { tebal beton }(\mathrm{m})
\end{array}
$$

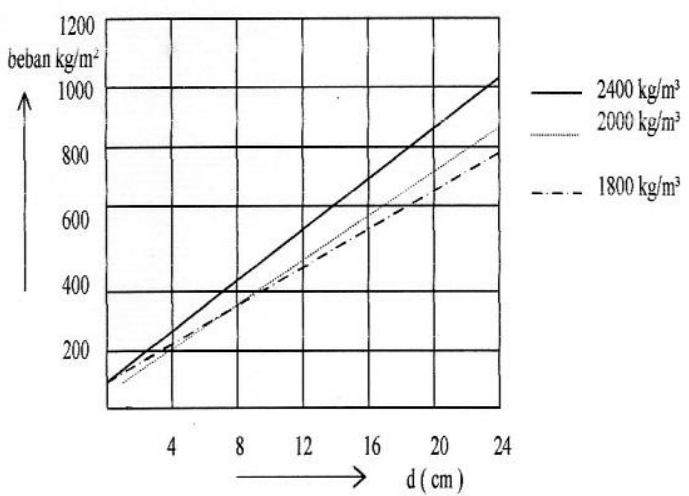

Gambar 2. Grafik untuk pembebanan lantai

Contoh : tebal lantai beton $=20 \mathrm{~cm}$ Digunakan beton bertulang maka pembebanan yang harus diperhitungkan :

$$
\begin{aligned}
& \mathrm{W} 1=2.400 \mathrm{~kg} / \mathrm{m}^{3} \times 0,20 \mathrm{~m}=480 \mathrm{~kg} / \mathrm{m}^{2} \\
& \mathrm{~W} 2=1 / 2 \times 480 \mathrm{~kg} / \mathrm{m}^{2}=240 \mathrm{~kg} / \mathrm{m}^{2} \\
& \mathrm{~W} 3==150 \mathrm{~kg} / \mathrm{m}^{2} \\
& \mathrm{~W} 1+\mathrm{W} 2+\mathrm{W} 3=870 \mathrm{~kg} / \mathrm{m}^{2}
\end{aligned}
$$

Balok

Yang perlu diperhitungkan :

- Berat sendiri beton

- kemungkinan menumpuknya beton disuatu tempat
Secara mathematis pembebanan untuk cetakan balok, dapat dirumuskan :

$\mathrm{W}=\gamma \times 1,5 \mathrm{~d}$
$\mathrm{~W}=$ beban $\left(\mathrm{kg} / \mathrm{m}^{2}\right)$
$\gamma=$ berat jenis beton

$\gamma=$ berat jenis beton
Tinggi balok $=65 \mathrm{~cm}$

$\mathrm{W} 1=2.400 \mathrm{~kg} / \mathrm{m}^{3} \times 0,65 \mathrm{~m}=1.560 \mathrm{~kg} / \mathrm{m}^{2}$

$\mathrm{W} 2=1.560 \mathrm{~kg} / \mathrm{m}^{3} \times 1 / 2=780 \mathrm{~kg} / \mathrm{m}^{2}$

$\mathrm{W}=\mathrm{W} 1+\mathrm{W} 2 \quad=2.340 \mathrm{~kg} / \mathrm{m}^{2}$

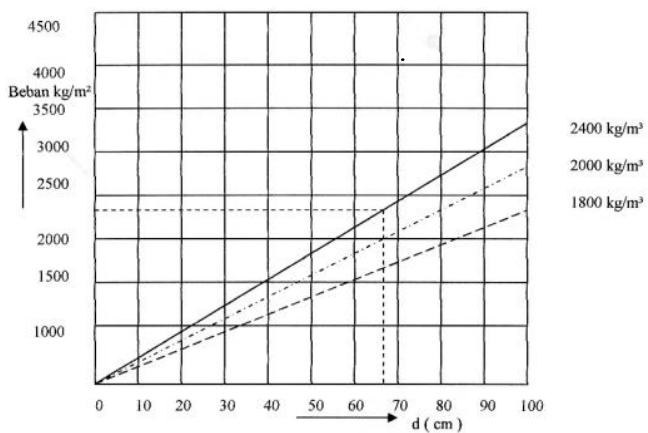

Gambar 2. Grafik untuk pembebanan balok

\section{Kolom dan Dinding.}

Pada prinsipnya pembebanan yang harus diperhitungkan adalah tekanan dari beton yang arahnya tegak lurus kolom/dinding.

Pada waktu pengecoran, beton masih berupa cairan, maka distribusi tekanan beton saat itu bersifat cairan, yang besarnya tergantung dari tinggi cairan, yang kita kenal sebagai $\gamma \mathrm{x} \mathrm{h}$, tetapi dengan waktu sifat beton akan berubah menjadi padat ( mengeras) maka beban yang harus diperhitungkan dipengaruhi oleh factor sebagai berikut :

- Tinggi pengecoran

- Kecepatan dari pengecoran

- Waktu

\section{SIRKULASI MATERIAL}

Sirkulasi material dimaksudkan untuk menghemat biaya. Pada prinsipnya, sirkulasi material ditentukan oleh jangka waktu curing dari beton, dan lamanya pelaksanaan tiap lantai.

Jangka waktu curing beton adalah tetap (disesuaikan spesifikasi), jadi untuk mempercepat sirkulasi material jangka waktu pelaksanaan tiap lantai haruslah dipercepat.

Untuk mengatur sirkulasi material agar diperhatikan :

- Waktu curing beton

- Jadual pelaksanaan

- Metode pelaksanaan cetakan

o bentuk Arsitektur 


\section{- cara pembongkaran}

Sebagai gambaran, diberikan sistem sirkulasi material. Data yang diperhatikan adalah:

- Waktu curing beton

Dinding \& kolom, dimana beton tidak mengalami lentur akibat berat sendiri, cetakan dapat dibongkar 1 sampai 2 hari

- Jadual pelaksanaan

Lama pelaksanaan adalah 15 hari per lantai

- Methoda pelaksanaan cetakan

Bentuk arsitektur : flat slab, untuk cetakan lantai digunakan sistem Flying shore.

Dari data diatas, maka sirkulasi material yang paling effisien adalah sebagai terlihat dalam diagram.

Tabel 2. Sirkulasi material

\begin{tabular}{|c|c|c|c|c|c|}
\hline Macam Ylantai & $\mathrm{i}$ & $i+1$ & $i+2$ & $i+3$ & $i+4$ \\
\hline $\begin{array}{l}\text { Lantai \& balok } \\
\text { (Flying shore) }\end{array}$ & 0 & & 0 & & $\stackrel{\bullet}{\longrightarrow}$ \\
\hline Kolom & 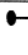 & & $\rightarrow$ & & $\stackrel{\bullet}{\longrightarrow}$ \\
\hline $\begin{array}{l}\text { Dinding Lift } \\
\text { (dalam) }\end{array}$ & $\bullet$ & $\rightarrow$ & 0 & & $\longrightarrow$ \\
\hline $\begin{array}{l}\text { Dinding Lift } \\
\text { (lwar) }\end{array}$ & 0 & & $\rightarrow$ & & $\stackrel{\bullet}{\rightarrow}$ \\
\hline Bearing wall & 6 & & & & \\
\hline
\end{tabular}

Khusus untuk dinding Bearing Wall, sirkulasi materialnya tidak setiap lantai, tetapi setiap tiga lantai, dibongkar setelah semua Flying shore dinaikkan kelantai selanjutnya. Dengan demikian pembongkarannya dan transportasinya mudah.

Karena waktu pembongkaran cetakan kolom dan balok / lantai berbeda, maka sistem sambungan antara cetakan kolom dan balok / lantai harus dapat dibongkar terpisah, hal demikian penting untuk direncanakan demi kemudahan bekerja.
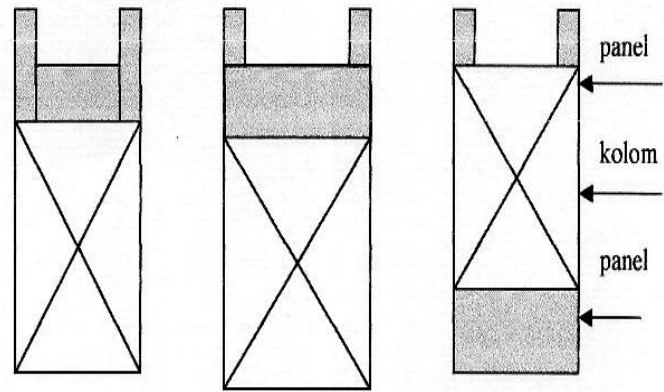

Gambar 5. Sistem panel kolom untuk memudahkan pembongkaran

\section{PERHITUNGAN CETAKAN}

Dasar perhitungan cetakan adalah sebagai berikut :

- $\quad($ lendutan $) \leq 0,30 \mathrm{~cm}$

- $\quad($ tegangan $) \leq$ ( tegangan yang dijinkan $)$

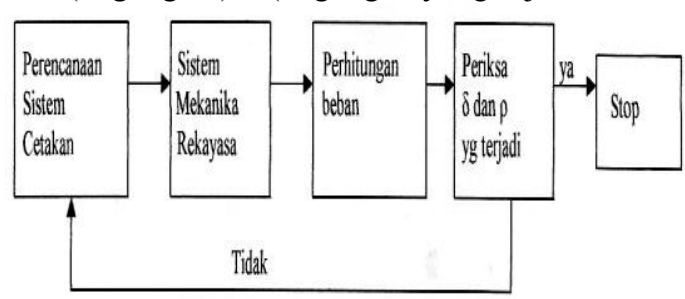

Gambar .6 Bagan alur cetakan

Perhitungan Momen ( M ) dan lendutan

( $)$

Dua tumpuan

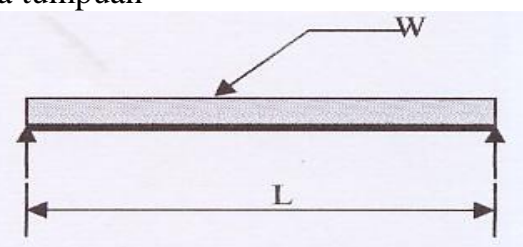

$$
\begin{aligned}
\mathrm{M} & =1 / 8 \mathrm{~W} \mathrm{\textrm {L } ^ { 2 }} \\
\delta & =\frac{5 W L^{22}}{384 E I}
\end{aligned}
$$

Menerus

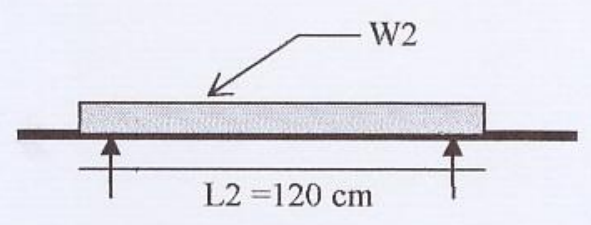

$$
\begin{aligned}
\mathrm{M} & =\frac{W L^{2}}{10} \\
\delta & =\frac{W L^{2}}{128 E I}
\end{aligned}
$$

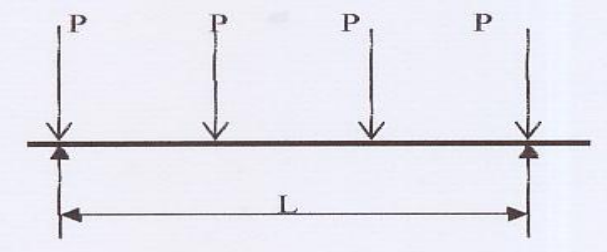

$$
\begin{aligned}
\mathrm{M} & =\frac{P L}{6} \\
\delta & =\frac{11 P L^{3}}{684 E I}
\end{aligned}
$$


Contoh Perhitungan untuk cetakan lantai .

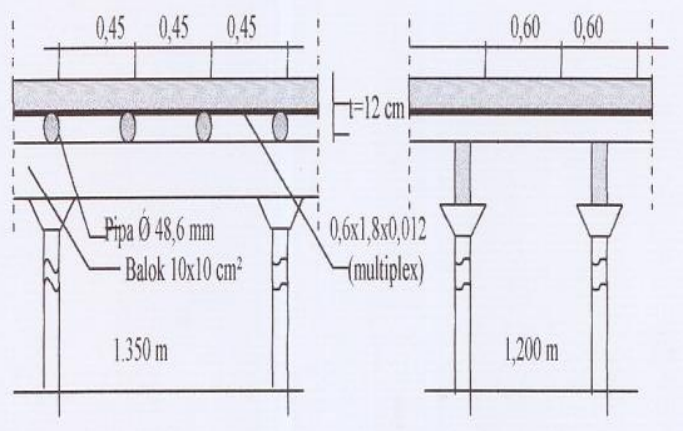

Gambar 7. Susunan cetakan

\section{Kayu Lapis / multiplex}

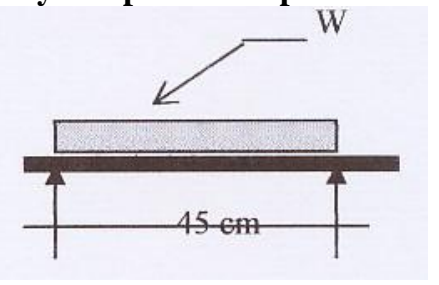

$\mathrm{W}=582 \mathrm{~kg} / \mathrm{m}^{2}$ (grafik pembebanan lantai) $\mathrm{w} 1=0,0582 \mathrm{~kg} / \mathrm{m}^{2} \times 60 \mathrm{~cm}=3,49 \mathrm{~kg} / \mathrm{cm}$

$\mathrm{M}=\frac{w 1 \cdot L t^{2}}{8}=883 \mathrm{~kg} \mathrm{~cm}$

$\Gamma=\frac{M}{Z}=61,30 \mathrm{~kg} / \mathrm{cm}^{2}<\Gamma$ ijin $=240 \mathrm{~kg} / \mathrm{cm}^{2}$

$\delta=\frac{5 \cdot w 1 \cdot L t^{22}}{384 E I}=0,308 \mathrm{~cm} \S 0,30 \mathrm{~cm}$

$\mathrm{Z}=1 / 6 \mathrm{bh}^{2}=1 / 6 \times 60 \times 1,2^{2}=14,4 \mathrm{~cm}^{3}$

$\mathrm{I}=1 / 12 \mathrm{bh}^{3}=1 / 12 \times 60 \times 1,2^{3}=8,64 \mathrm{~cm} 4$

\section{Kaso / pipa}

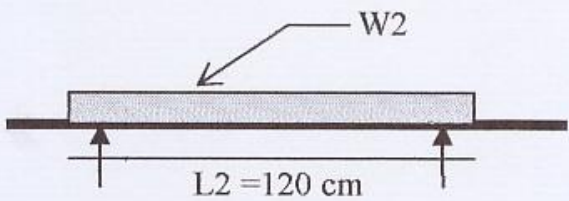

$\mathrm{W}=0,0582 \mathrm{~kg} / \mathrm{cm}^{2}$

$\mathrm{w} 2=\mathrm{W}$ x L1 $=0,0582 \mathrm{~kg} / \mathrm{cm}^{2} \times 45 \mathrm{~cm}$

$=2,62 \mathrm{~kg} / \mathrm{cm}$

$\mathrm{M}=\frac{w 2 \cdot L^{2}}{10}=3,370 \mathrm{~kg} \mathrm{~cm}$

$\Gamma=\frac{M}{Z}=984 \mathrm{~kg} / \mathrm{cm}^{2}<1600 \mathrm{~kg} / \mathrm{cm}^{2}$
$\delta=\frac{W 2 \cdot L 2^{22}}{128 E I}=0,217 \mathrm{~cm}<0,30 \mathrm{~cm}$

Balok

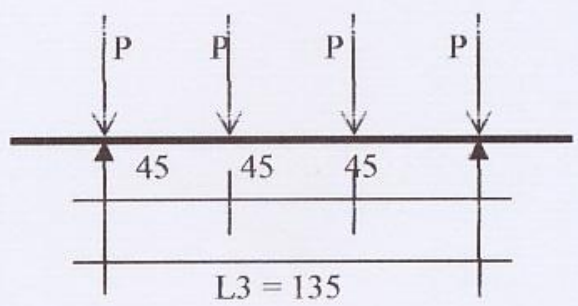

$$
\begin{aligned}
\mathrm{W} & =0,0582 \mathrm{~kg} / \mathrm{cm}^{2} \\
\mathrm{P} & =\mathrm{W} \times \mathrm{L} 1 \times \mathrm{L} 2 \\
& =0,0582 \times 45 \times 120 \\
& =314 \mathrm{~kg}
\end{aligned}
$$

$\mathrm{M}=\frac{P L 3}{6}=7,070 \mathrm{~kg} \mathrm{~cm}$

$\Gamma=\frac{M}{Z}=42,42 \mathrm{~kg} / \mathrm{cm}^{2}<105 \mathrm{~kg} / \mathrm{cm}^{2}$

$\delta=\frac{11 P L 3^{3}}{684 E I}=0,2248 \mathrm{~cm}<0,30 \mathrm{~cm}$

\section{Perancah ( support / tiang )}

$\mathrm{W}=0,582 \mathrm{~kg} / \mathrm{cm}^{2}$

$\mathrm{N}=\mathrm{W} \times \mathrm{L} 2 \times \mathrm{L} 3 \times 1,1$

$=0,582 \times 120 \times 135 \times 1,1 \mathrm{~kg}$

$=1.037 \mathrm{~kg}<1.500 \mathrm{~kg}(\mathrm{~N}$ ijin $)$.

\section{KESIMPULAN}

- Dalam pembangunan gedung bertingkat , akan lebih efisien apabila bekisting menggunakan bahan yang kuat sehingga dapat dipakai beberapa kali.

- Untuk bangunan gedung 2 (dua) lantai dengan menggunakan plafond, dapat dipakai dengan menggunakan papan bekisting, apabila expose (tanpa plafond) maka papan bekisting dilapisi dengan tripleks dan plastik lembaran.

- Bekisting balok yang dirancang dengan sistem bongkar pasang, dimana balok tersebut dirancang khusus untuk segmen tertentu.

- Dengan cara sewa dapat dilakukan untuk mengurangi limbah yang dapat mengganggu lingkungan. 


\section{DAFTAR PUSTAKA}

1. A.P. Potma, Ir - J.E. De Vries,1953, Konstruksi Baja, Jakarta.

2. Dharma Niaga PT. (LTD), Tabel baja/besi (Weight List), Distributor PT. Krakatau Steel dan Pedagang besi-besian,- Jakarta

3. Harianto Hardjasaputra, Ir. Construction Engineering, Metoda pelaksanaan struktur Ratu Plaza,- Jakarta, P.T. Waskita Kajima Corporation Indonesia

4. Istimawan Dipohusodo, 1994, Struktur Beton Bertulang, berdasarkan SK SNI T15-1991-03 Departemen Pekerjaan Umum RI ， Jakarta , Gramedia Pustaka Utama.
5. J. Honing Ir, 1982.Baja Bangunan- G.J. Weetzel, Jakarta , PT. Pradnya Paramita.

6. Peraturan Beton Bertulang Indonesia 1971 - NI-2, Depertemen Pekerjaan Umum dan Tenaga Listrik Direktorat Jenderal Cipta Karya Lembaga Penyelidikan Masalah Bangunan

7. Peraturan Konstruksi Kayu Indonesia (PKKI) NI-5

8. Sumanto, Drs, MA, 1996,. Pengetahuan Bahan, Andi Offset, Yogyakarta .

9. Sumono,R. Ilmu Gaya, Jambatan,- Jakarta.

10. Suwarno Wiryomartono, Konstruksi kayu, Universitas Gadjah Mada, Yogyakarta 